\title{
Want to block earworms from conscious awareness? B(u)y gum!
}

Article

Accepted Version

Beaman, C. P., Powell, K. and Rapley, E. (2015) Want to block earworms from conscious awareness? B(u)y gum! Quarterly Journal of Experimental Psychology, 68 (6). pp. 1049-1057. ISSN 1747-0218 doi: https://doi.org/10.1080/17470218.2015.1034142 Available at https://centaur.reading.ac.uk/40114/

It is advisable to refer to the publisher's version if you intend to cite from the work. See Guidance on citing.

To link to this article DOI: http://dx.doi.org/10.1080/17470218.2015.1034142

Publisher: Taylor \& Francis (Routledge)

All outputs in CentAUR are protected by Intellectual Property Rights law, including copyright law. Copyright and IPR is retained by the creators or other copyright holders. Terms and conditions for use of this material are defined in the End User Agreement.

\section{www.reading.ac.uk/centaur}

\section{CentAUR}

Central Archive at the University of Reading 
Reading's research outputs online 
Want to block earworms from conscious awareness? B(u)y gum!

C. Philip Beaman ${ }^{1,2}$, Kitty Powell ${ }^{2}$, Ellie Rapley ${ }^{2}$

${ }^{1}$ Centre for Cognition Research, University of Reading

${ }^{2}$ School of Psychology \& Clinical Language Sciences, University of Reading

Running Head: BLOCKING EARWORMS

Corresponding author:

C. Philip Beaman,

School of Psychology \& Clinical Language Sciences

University of Reading

Earley Gate, Whiteknights

Reading RG6 6AL

UK

Email: c.p.beaman@ reading.ac.uk

Telephone: +44 (0) 1183787637

Word Count: 3, 345

Keywords:

Earworms, Auditory Imagery, Thought Suppression, Music Cognition, Short-Term Memory 


\begin{abstract}
Three experiments examine the role of articulatory motor planning in experiencing an involuntary musical recollection (an "earworm"). Experiment 1 shows that interfering with articulatory motor programming by chewing gum reduces both the number of voluntary and involuntary - unwanted -musical thoughts. This is consistent with other findings that chewing gum interferes with voluntary processes such as recollections from verbal memory (Kozlov, Hughes \& Jones, 2012) the interpretation of ambiguous auditory images (Reisberg, Smith, Baxter \& Sonenshine, 1989) and the scanning of familiar melodies (Smith, Wilson \& Reisberg, 1995) but is not predicted by theories of thought suppression which assume that suppression is made more difficult by concurrent tasks or cognitive loads (Wenzlaff \& Wegner, 2000). Experiment 2 shows that chewing the gum affects the experience of "hearing" the music and cannot be ascribed to a general effect on thinking about a tune only in abstract terms. Experiment 3 confirms that the reduction of musical recollections by chewing gum is not the consequence of a general attentional or dual-task demand. The data support a link between articulatory motor programming and the appearance in consciousness of both voluntary and unwanted musical recollections.
\end{abstract}


An "earworm" is a tune that arises seemingly spontaneously and becomes "stuck" in the head. Most earworms are excerpts of familiar and recently experienced songs (Beaman \& Williams, 2010), suggesting that an earworm may be a form of involuntary musical memory (Liikkanen, 2012) analogous with involuntary autobiographical or semantic memories (e.g., Kvavilsahvili \& Mandler, 2004). The involuntary experience of music is reported by the majority of those queried in questionnaire studies (Beaman \& Williams, 2010). Many respondents report that the involuntary experience of music is not unpleasant, and it may even be actively welcomed but unwanted musical images which recur are also rated as the most intrusive of common involuntary cognitions. They were described as "hateful" by Sacks (2007) and, in the earliest known literary record of the phenomenon, Edgar Allan Poe describes how it is, "quite a common thing" to be "annoyed" or "tormented" by "the ringing in our ears, or rather in our memories, of the burthen of some ordinary song" (Poe, 1845). An extreme account of their negative impact also forms the plot of a short story by Mark Twain (1876), and the question of how to rid oneself of an earworm is also regularly raised by more modern media (e.g., http://www.bbc.co.uk/news/magazine-17302237). Interviewees on recent $\mathrm{BBC}$ radio broadcast reporting on earworms from a musical perspective (PM programme, BBC Radio 4, $15^{\text {th }}$ December 2014) described the phenomenon of involuntary music as increasingly intrusive over time ("more and more it does bother me... an obstacle to thinking and concentrating and reading", "something you've got to watch out for" and "very, very disturbing for some people") ${ }^{1}$. Thus, the earworm - and the musical hallucination more generally - represents an instance of the wider question of how mental control is achieved, specifically the longstanding question of how unwanted images and memories are suppressed or otherwise excluded from consciousness.

\footnotetext{
${ }^{1}$ The interviewees quoted here were an academic philosopher who reports hearing a "perpetual music track", Martin Evans, and the Director of Music at St Catharine's College, Cambridge, Edward Wickham.
} 
One questionnaire study (Beaman \& Williams, 2013) indicated that participants scoring highly on the white bear suppression inventory (WBSI; Wegner \& Zanakos, 1994), an indicator of mental control, reported earworms of shorter duration than those who scored less highly on this inventory. This type of mental control has been linked to general cognitive resources; high-capacity individuals show greater ability to suppress (Brewin \& Smart, 2005). Hyman et al. (2012) likewise implicated cognitive load in the appearance of earworms however the relationship was non-monotonic: songs "returned" during low cognitive load periods, and high cognitive loads also increased intrusive song frequency, implying that the relationship between an involuntary musical image and cognitive load may be more complex than reported in previous investigations of deliberate thought suppression.

To try and investigate the relationship between earworms and mental control in a more principled and theoretically informed manner, we used a standard method of investigating thought suppression, asking participants to try not to think of the target item (in this case, a tune to which they were previously exposed) and to indicate whenever the tune came to mind unbidden (cf., Wegner, 1994). Alongside the deliberate suppression of the song, however, we also introduced a manipulation, informed by a separate body of research, which was designed to reduce the "potency" of this unwanted auditory imagery. Work by Andrade and her colleagues (Andrade, Kavanagh \& Baddeley, 1997; Baddeley \& Andrade, 2000) has indicated that the vividness of images can be reduced by sensory-specific stimulation. Thus, emotionally-charged visual images were rated as less vivid by participants concurrently engaged in making experimenter-prescribed saccadic eye-movements (Andrade et al., 1997) and auditory images were rated as less vivid when simultaneously engaged in a counting task intended to load on sub-vocal rehearsal. More pertinently, data specific to auditory imagery (Reisberg et al., 1989; Smith et al., 1995) show that irrelevant subvocalisation also impedes the re-interpretation of an ambiguous auditory image and the 
scanning of familiar melodies, which Reisberg and colleagues have interpreted as showing a link between the "inner ear" (auditory/phonological storage) and the "inner voice" (sub-vocal rehearsal). For the earworm, therefore, it seems likely that manipulations intended to render the earworm less frequent should also involve sub-vocalisation, or sub-vocalisation-like processes, but these need not be specifically verbal in nature given that some earworms are for tunes - or parts of tunes - without verbal or lyrical content (e.g., Beaman \& Williams, 2010).

Consistent with this idea, an intriguing suggestion from an anonymous online commenter is that s/he found chewing on a cinnamon stick an effective counter to an earworm (www.exploratorium.edu/music/questions/earworm.html). This is particularly suggestive because sub-vocalisation (or "inner speech") effects on short-term memory processes are suggested to depend upon articulatory motor programming rather than articulation per se (Bishop \& Robson, 1989), and also because chewing gum has been shown to act in a similar manner to irrelevant sub-vocalisation in degrading both short-term memory performance (Kozlov et al., 2012) and auditory imagery (Smith et al., 1995). However, the data on sub-vocalisation and auditory imagery reported both by Andrade and colleagues and Reisberg and colleagues address the quality of a voluntarily-generated auditory imagery rather than the reasons why an auditory image is recalled and why appears in conscious awareness. Arguably, irrelevant sub-vocalisation compromises voluntary recall by degrading the quality of a verbal memory representation (e.g., Nairne, 1990). If so, reducing the quality of an auditory-musical representation by the same means could reduce the likelihood that an involuntary musical recollection is experienced. The effect of irrelevant sub-vocalisation may, however, depend upon the nature of auditory-musical representation and of rehearsal. If the representation is maintained or supported by articulatory motor programming, rather than by a specifically verbal code, then chewing should degrade the representation (or at least, 
prevent it from being refreshed; Kozlov et al., 2012; Macken \& Jones, 1995) whereas if a phonemic or verbal code of some kind is underlying the auditory image it might be necessary to specifically engage speech production mechanisms in order to disturb the image and, in this case, chewing should not affect the appearance of a musical recollection.

From a less theoretical and more applied perspective, countering earworms by chewing gum is likely to be a more practical approach than, for example, attempting the anagrams which Hyman et al (2012) found effective. The first experiment therefore examines whether "loading" articulatory motor programmes by means of chewing gum impacts upon the conscious appearance of an intrusive musical image which participants are specifically asked to try not to think about.

As a subsidiary hypothesis, we also examine whether an earworm might "rebound" in some way and become either more or less accessible once attempts to suppress it have ceased. Rebound effects occur subsequent to deliberate suppression when participants who have previously suppressed a thought report experiencing that same thought more frequently than others who have not undergone the initial suppression period (Wegner \& Erber, 1992) 2 . Unlike the standard "rebound" investigation, which compares groups asked to suppress a thought with those asked to concentrate on the thought, here we are concerned with the conscious experience of music after suppression instructions with or without gum-chewing. A main effect of time period (suppression or expression period) would thus indicate an overall difference in the voluntary versus involuntary experience of the music and an interaction between suppression/expression and gum-chewing might - dependent upon the form it took indicate that chewing impacted only upon either the attempted involuntary recollection during suppression or only upon the post-suppression voluntary recollections.

\footnotetext{
${ }^{2}$ Although a contrasting pattern - poorer memory for previously ignored material that is now being re-presented for recall (Marsh, Beaman, Hughes \& Jones, 2012) - has also been reported.
} 


\section{Experiment One}

Method.

Participants. Forty-four undergraduate students (10 male) participated in return for course credit.

Materials and Design. The song participants were asked not to think about was "Play Hard" by David Guetta featuring Flo Rida and Akon. The gum/ no-gum conditions were counterbalanced in a repeated-measures design. ELMA sugar free mastic gum was used because of its solid texture and mild flavour.

Procedure. Participants were played the first 30s of the song (the chorus) twice to ensure they were familiar with the tune. They were then exposed to either the gum or no-gum condition. For the no-gum condition they were asked to try not to think of the music they had just heard for a timed three minute period. The instructions stated simply that they could sit and think about whatever they wished for the next three minutes provided they did not think of the tune they had just heard. They were asked, every time they found themselves thinking of the music, to indicate this by pressing the " $\mathrm{q}$ " key on a computer keyboard in front of them. Following this suppression period, participants were next asked to think freely for a further three minutes about anything they wished, which might include the music they had just heard. Once again, however, they were asked to press the "q" key whenever the tune came to mind. The gum condition was identical to the no-gum condition except that participants were supplied with the chewing gum at the start of the condition and asked to chew it "vigorously". All participants were exposed to both gum and no-gum conditions, the order of which was counterbalanced across participants. 
Results.

The results of this experiment are shown in Figure 1. A repeated measures analysis of variance (ANOVA) on the number of key-presses revealed a main effect of chewing gum $F(1,43)=9.23, M S E=387.05, \eta_{\mathrm{p}}{ }^{2}=.18, p=.004$, indicating that gum-chewing reduced the number of key-presses corresponding to awareness of the music at any point during the experiment, but no effect of time period $F(1,43)=.37, M S E=11.51, \eta_{\mathrm{p}}{ }^{2}=.01, p=.54$ and no interaction, $F(1,43)=.58, M S E=10.51, \eta_{\mathrm{p}}^{2}=.01, p=.45$.

\section{FIGURE ONE ABOUT HERE}

\section{Discussion}

The results indicate that gum-chewing reduced the number of times the music was consciously experienced and reported in both music-suppression conditions and an overt expression condition where participants were free to think about the music. This is consistent with the hypothesis that gum-chewing interferes with the formation of the auditory imagery needed to experience an involuntary musical recollection. The lack of any main effect of suppression/expression instructions indicates that the music was equally accessible at both periods of the experiment - when participants were free to voluntarily recollect the music and when they were asked to suppress the tune. The absence of any interaction also indicates that the effect of the gum was equivalent across both involuntary (suppression condition) musical recollections and an expression condition in which participants were free to voluntarily recollect the music if they so wished. The results of this experiment are, however, subject to the criticism that participants were only reporting thoughts of the music - indicating when they became aware that they were thinking about the title of the music or some other feature- 
whereas the predictions were that gum-chewing would interfere with the involuntary experience of the music, i.e., "hearing" the tune in one's mind. Whereas both conditions might reasonably be classified as instances of an unwanted thought, arguably the musical content and experience is necessary for this thought to be considered an "earworm". For example, in their survey, Beaman and Williams (2010, p. 653) described the phenomenon as tunes "that get stuck in your head even though you do not want them there" implying that the experience of "hearing" the music is a defining characteristic of the earworm. In Experiment 1 , however, there is no evidence that the music is "heard" in either condition, much less that this experience is reduced by chewing gum. Experiment 2 is designed to test this possibility.

\section{Experiment Two}

Method.

Participants. Eighteen undergraduate students participated in return for course credit.

Materials and Design. These were identical to Experiment 1, with the exception that no postsuppression "rebound" period was included.

Procedure. This was identical to Experiment 1, with the exception that participants were asked to press the "q" key whenever the song came to mind simply as a thought, and to press the " $p$ " key whenever they experienced the music playing in their heads.

Results.

The results of the experiment are given in Figure 2. The sum of the "thoughts" and "music" responses are comparable to the "earworms" in each of the suppress conditions shown in Figure 1. There was a main effect of gum, $F(1,17)=16.73, M S E=2.08, p=.001, \eta_{\mathrm{p}}{ }^{2}=.5$ and 
response, $F(1,17)=33.24, M S E=5.06, p<.001, \eta_{\mathrm{p}}{ }^{2}=.66$ but the interaction was not significant, $F(1,17)=2.23, \operatorname{MSE}=.15, p=.15, \eta_{\mathrm{p}}^{2}=.17$.

\section{FIGURE TWO ABOUT HERE}

Discussion.

These data confirm the effect of chewing gum on the appearance of to-be-supressed thoughts and indicate also that both the majority of the involuntary musical thoughts and the bulk of the effect of chewing is upon the experience of "hearing" a tune, that is upon experiencing an earworm ${ }^{3}$. However, neither Experiments 1 or 2 contained a general attentional control, so it remains possible that the effects of chewing gum observed here are common to any kind of motor activity and not specific to the articulators. Experiment 3 tests this possibility.

\section{Experiment Three}

Method.

Participants. Thirty-six undergraduate students (28 female) participated in return for course credit. Their age range was between 18 and 27 (mean $=19.9)$.

Materials and Design. These were identical to Experiment 1 with the exceptions that a different tune was used (Payphone by Maroon 5), this was played in full for two minutes prior to each experimental condition, and there were three conditions. The gum and no-gum conditions were identical to those of Experiment 1. In the tapping condition, participants

\footnotetext{
3 "Earworms" are highly idiosyncratic and individual when encountered in an everyday setting, a situation which is difficult to replicate experimentally, but we take the experiential aspect of unwanted music playing "in the head" (which this experiment has replicated) to be the defining features of the phenomenon.
} 
were asked to tap continuously upon the desk with each of the fingers of their dominant hand in turn. The order of presentation of the conditions was counterbalanced across participants.

Procedure. This was identical to Experiment 1, with the exceptions that the "w" key was used for collecting responses and only two minutes were spent in each of the three thoughtsuppression conditions.

Results.

The results of the experiment are given in Figure 3. There was a main effect of interference condition, $F(2,68)=3.99, M S E=195.64, p=.046, \eta_{\mathrm{p}}{ }^{2}=.11$ and paired sample $\mathrm{t}-$ tests revealed a significant difference between tapping and chewing conditions, $t(35)=2.36$, $p=.02$ but no significant differences between tapping and control conditions, $t(35)=1.68, p$ $=.10$ (both tests 2 -tailed). These data are consistent with the notion that motor activity per se (tapping) is less effective than motor activity which is specifically sub-vocal as a general dual-task or attentional distraction and a means of moderating the involuntary appearance of unwanted musical recollections or earworms.

\section{FIGURE THREE ABOUT HERE}

\section{General Discussion}

These data are consistent in demonstrating that an articulatory motor activity - in this case, chewing gum - interferes with the experience of "hearing" musical recollections both voluntarily, or at any rate without any specific instruction to suppression the recollection, (Experiment 1, expression condition) and involuntarily (Experiment 1, suppression condition; 
Experiments $2 \& 3$ ). A non-significant interaction in Experiment 2 means that we cannot rule out the possibility that chewing the gum has a general effect on thought suppression and not just a specific impact upon the experience of "hearing" a tune, but Experiment 2 is nonetheless clear in showing the majority of the effect of the gum is on the experience of an auditory (in this case, musical) stimulus, reducing the number of times the tune reappeared. Experiment 3 rules out the possibility that the effect observed is a general effect of motor activity and not specific to interfering with sub-vocalisation. Although a numerical difference exists between tapping and control, the only statistically significant difference was between chewing and tapping, indicating that chewing has an effect over and above that of simple motor activity.

The data support the anecdotal report of the anonymous on-line commentator who stated that chewing on cinnamon sticks eliminated his/her earworms. At a practical level, therefore, chewing gum can be recommended as an aid to reduce unwanted musical recollections. The results are also of theoretical interest. The activity of chewing gum - or any articulatory motor activity - has not previously been shown to impact on thought suppression or mental control generally. The direction of the effect (reducing the number of "earworms" experienced) is opposite to that expected based upon other investigations, which indicate that participants given an extra activity or cognitive load show poorer suppression (Wenzlaff \& Wegner, 2000). The reason for this, however, is straightforward. The simple act of chewing gum does not create a general cognitive load (as, for example, a repeated vocalisation likewise has specific, not general effects on cognition, e.g., Baddeley \& Andrade, 2000) so thought suppression per se is largely unaffected. Rather, co-opting the articulatory motor programme to chew the gum impairs the involuntary recollection of an auditory image. This is consistent with data showing that chewing gum can affect immediate memory for verbal material (Kozlov et al., 2012) and that occupying articulatory motor 
processes has a negative impact upon the vividness of auditory imagery (Baddeley \& Andrade, 2000) and the ability to further process auditory images to resolve ambiguities within the image (Reisberg et al., 1989) or to scan familiar melodies in search of a particular target note (Smith et al., 1995). The consistency of these disparate data-sets is supportive of a common processing link between articulatory motor programmes, immediate verbal memory and auditory imagery that may be experienced either voluntarily or - as here - involuntarily.

The data also raise a number of interesting possibilities. A recent review of empirical data on auditory imagery (Hubbard, 2010) highlights the selective nature of manipulations designed to interfere with inner speech. For example, such manipulations decrease the ability to judge the pitch of a melody or to interpret an ambiguous image (e.g., Smith et al., 1995) whereas other tasks such as judging voiced vs. unvoiced consonants are unaffected (see Hubbard, 2010). The current data add to the list of processes which seem to rely upon subvocalisation, even if involuntarily, but the contribution of such processes to all forms of unwanted thought is still unclear. There is, for example, no evidence that patients prone to auditory hallucinations are either more or less capable at tasks which Smith and colleagues (Smith, 1992; Smith et al., 1995) suggested required the use of sub-vocal motor programming (Evans, McGuire \& David, 2000). Thus, although chewing gum may aid in the reduction of unwanted musical recollections, hallucinatory experiences of a psychotic nature may involve different processes.

The nature of the interference with sub-vocal motor processes is also of interest. Concurrent articulation could conceivably be particularly disruptive of verbal short-term memory because both involve phonological or verbal representations (e.g., Nairne, 1990) but the current data are consistent with the possibility that the interference is at the somewhat more general level of vocal motor-programming (Kozlov et al., 2012; Macken \& Jones, 1995). A possible goal for a future study is whether or not irrelevant sub-vocalisation that has 
verbal content might be even more effective, at least when the musical imagery also has verbal content. Earworms with lyrical content versus those which are instrumental only, and their interaction with various sorts of irrelevant motor programming, might provide a novel means of investigating these issues. Data also suggest that sub-vocal "inner speech" is used to aid task-switching (Emerson \& Miyake, 2003) and potentially other executive functions. Disabling inner speech by means of an irrelevant sub-vocal motor programming (such as chewing) might therefore ordinarily be expected to impede thought suppression by interfering with such executive functions in a similar manner to imposing a cognitive load. In contrast, the current study indicates that interference with inner speech might, under the correct circumstances, help to obtain the sorts of outcome (e.g., fewer unwanted intrusions) that would normally require an executive inhibitory process. In our study the dual-task interference aided, rather than hindered, attempts to reach the task goal. 


\section{References.}

Andrade, J., Kavanagh, D., \& Baddeley, A. (1997). Eye-movements and visual imagery: A working memory approach to the treatment of post-traumatic stress disorder. British Journal of Clinical Psychology, 36, 209-233.

Baddeley, A. D. \& Andrade, J. (2000). Working memory and the vividness of imagery. Journal of Experimental Psychology: General, 129, 126-145.

Beaman, C. P., \& Williams, T. I. (2010) Earworms ("stuck song syndrome"): Towards a natural history of intrusive thoughts. British Journal of Psychology, 101, 637-653.

Beaman, C. P., \& Williams, T. I. (2013). Individual differences in mental control predict involuntary musical imagery. Musicae Scientiae, 17, 398-409.

Bishop, D. V. M., \& Robson, J. (1989). Unimpaired short-term memory and rhyme judgment in congenitally speechless individuals: Implications for the notion of "articulatory coding". Quarterly Journal of Experimental Psychology, 41A, 123-140.

Brewin, C. R., \& Smart, L. (2005). Working memory capacity and the suppression of intrusive thoughts. Journal of Behavior Therapy \& Experimental Psychiatry, 36, 61-68.

Emerson, M. J., \& Miyake, A. (2003). The role of inner speech in task switching: A dualtask investigation. Journal of Memory \& Language, 48, 148-168.

Evans, C. L., McGuire, P. K., \& David, A. S. (2000). Is auditory imagery defective in patients with auditory hallucinations? Psychological Medicine, 30, 137-148.

Hubbard, T. L. (2010). Auditory imagery: Empirical findings. Psychological Bulletin, 136, 302-329.

Hyman, I. E., Burland, N. K., Duskin, H. M., Cook, M. C., Roy, C. M., McGrath, J. C., \& Roundhill, R. F. (2012). Going gaga: Investigating, creating and manipulating the song stuck in my head. Applied Cognitive Psychology, 27, 204-215. 
Kozlov, M. D., Hughes, R. W., \& Jones, D. M. (2012). Gummed-up memory: chewing gum impairs short-term recall. Quarterly Journal of Experimental Psychology, 65, 501-513.

Kvavilashvili, L., \& Mandler, G. (2004). Out of one's mind: a study of involuntary semantic memories. Cognitive Psychology, 48, 47-94.

Liikkanen, L. A. (2012). Inducing involuntary musical imagery: An experimental study. Musicae Scientiae, 16, 217-234.

Macken, W. J., \& Jones, D. M. (1995). Functional characteristics of the inner voice and the inner ear: Single or double agency? Journal of Experimental Psychology: Learning, Memory, \& Cognition, 21, 436-448.

Marsh, J. E., Beaman, C. P., Hughes, R. W., \& Jones, D. M. (2012). Inhibitory control in memory: Evidence for negative priming in free recall. Journal of Experimental Psychology: Learning, Memory \& Cognition, 38, 1377-88

Nairne, J. S. (1990). A feature model of immediate memory. Memory \& Cognition, 18, 251269.

Poe, E. A. (1845/ 1938). The imp of the perverse. Reprinted in The complete tales and poems of Edgar Allan Poe. New York: Random House.

Reisberg, D., Smith, J. D., Baxter, D. A., \& Sonenshine, M. (1989). "Enacted” auditory images are ambiguous: "pure” auditory images are not. Quarterly Journal of Experimental Psychology, 41A, 619-641.

Sacks, O. (2007). Musicophilia: Tales of music and the brain. New York: Random House.

Smith, J. D. (1992). The auditory hallucinations of schizophrenia. In D. Reisberg (Ed.), Auditory imagery (pp. 151-178). Hillsdale, NJ: Erlbaum.

Smith, J. D., Wilson, M., \& Reisberg, D. (1995). The role of subvocalization in auditory imagery. Neuropsychologia, 33, 1433-1454. 
Twain, M. (1876/1878). A literary nightmare. Reprinted in Punch, brothers, punch! and other stories. New York: Slote, Woodman \& Co.

Wegner, D. (1994). Ironic processes of mental control. Psychological Review, 101, 34-52.

Wegner, D. M., \& Erber, R. (1992). The hyperaccessibility of suppressed thoughts. Journal of Personality \& Social Psychology, 63, 903-912.

Wegner, D. M., \& Zanakos, S. (1994). Chronic thought suppression. Journal of Personality, 62, 615-640.

Wenzlaff, R. M., \& Wegner, D. M. (2000). Thought suppression. Annual Review of Psychology, 51, 59-91. 


\section{Acknowledgements}

We are grateful to Rozeena Zeb and Ayyub Hanid for their help in running Experiment 3. The research reported in this article was partly supported by Economic and Social Research Council (ESRC) grant ES/L00710X/1 awarded to the first author. Thanks to Lassi Liikkanen for drawing our attention to the quotation from E. A. Poe's (1845) short story, The Imp of the Perverse. 


\section{Figure Captions.}

Figure 1. Data showing the number of times the suppressed tune (or "earworm") came to mind during a timed 3-minute period of suppression or free expression in gum-chewing and no-gum control conditions. Error bars are standard error.

Figure 2. Data showing the number of times participants reported thinking of the suppressed tune ("Thought" condition) or "hearing" the music in their head ("Music" condition) during a timed 3-minute period of suppression in gum-chewing and no-gum control conditions. Error bars are standard error.

Figure 3. Data showing the number of times participants report thinking of a suppressed tune in gum chewing, general distractor (tapping), and a no distractor control conditions. Error bars are standard error. 
FIGURE ONE

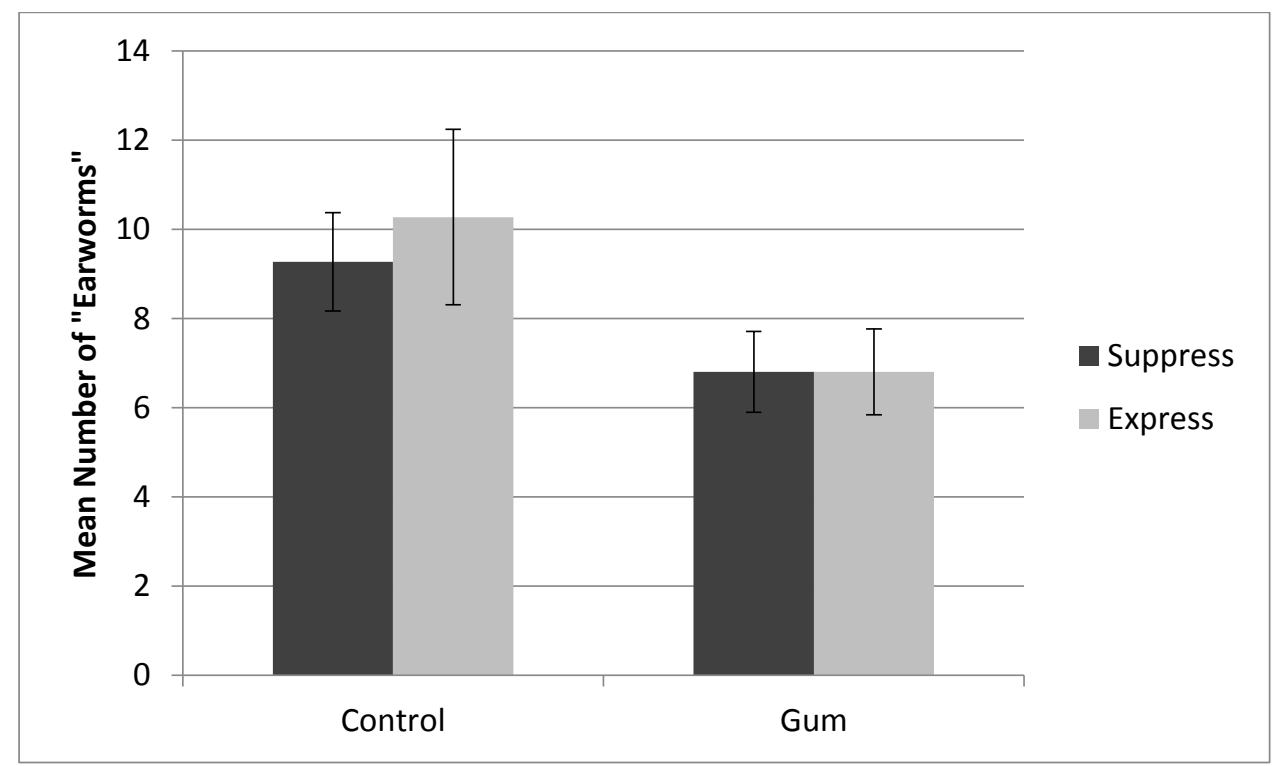


FIGURE TWO

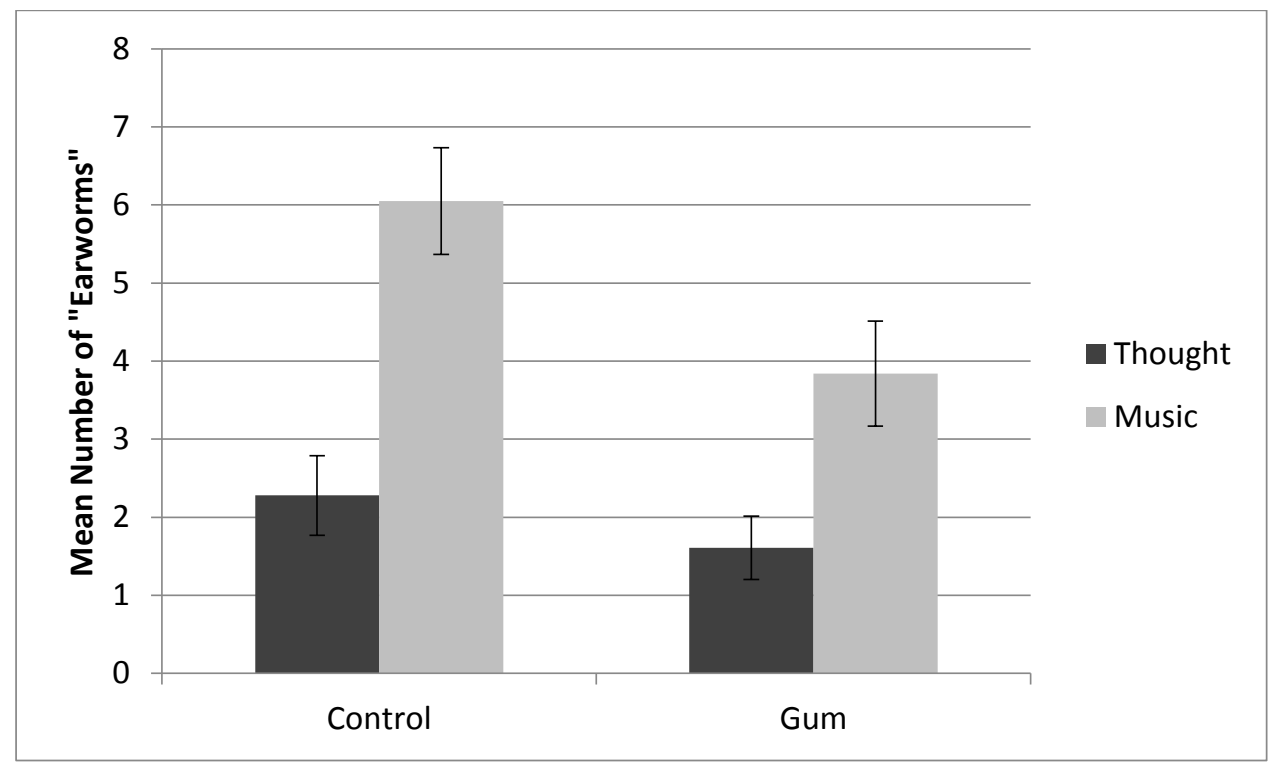


FIGURE THREE

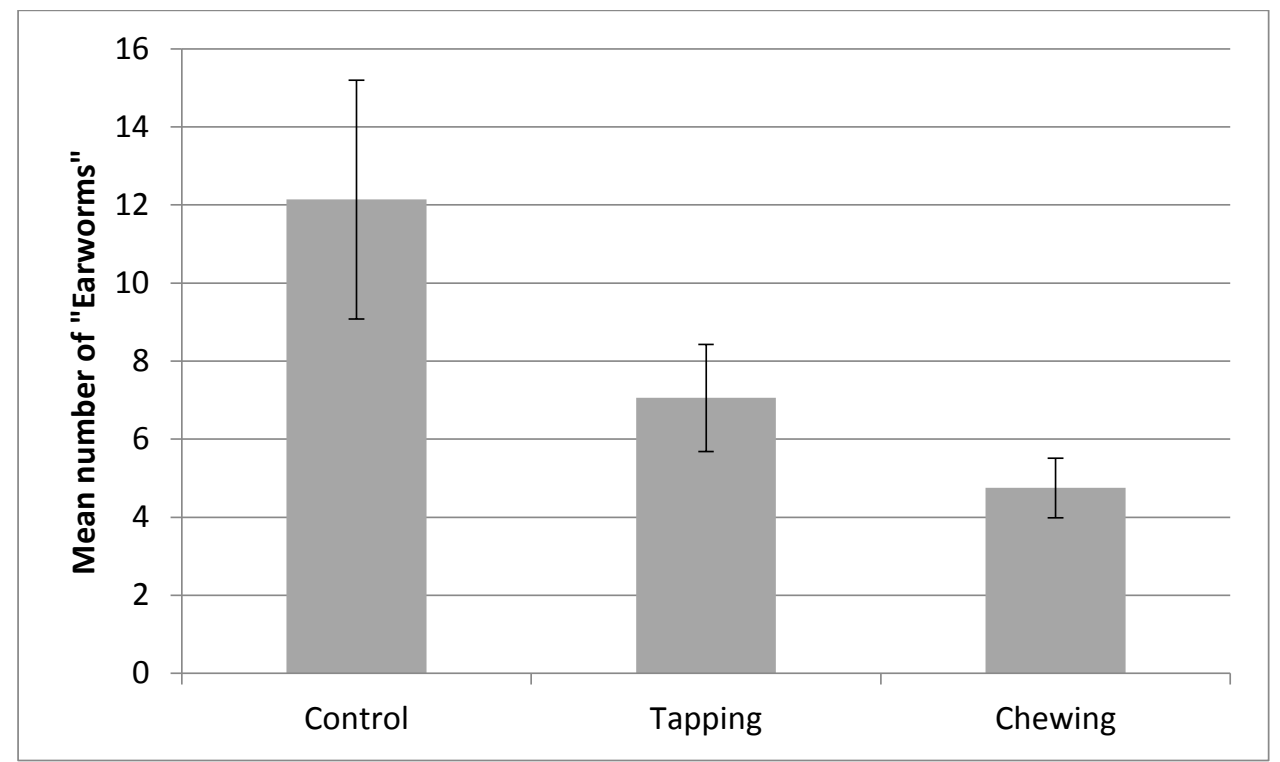

